\title{
LA-UR $96-1773$
}

$$
\text { CONF- } 951155-122
$$

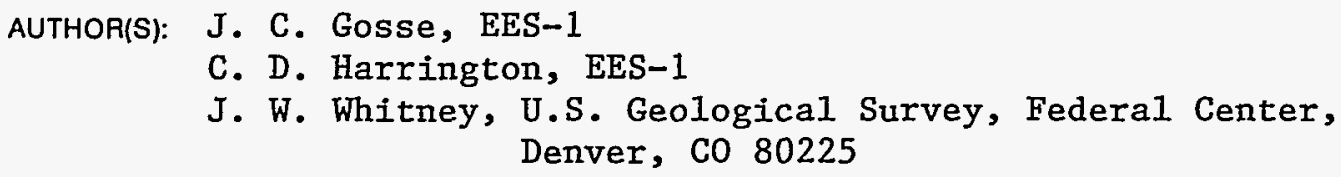

SUBMITTED TO: Materials Research Society Symposium

Vo1. 412

November 27 - December 1, 1995

Boston, MA 


\title{
APPLICATIONS OF IN SITU COSMOGENIC NUCLIDES IN THE GEOLOGIC SITE CHARACTERIZATION OF YUCCA MOUNTAIN, NEVADA
}

\author{
J. C. GOSSE*, C. D. HARRINGTON*, J. W. WHITNEY** \\ *EES-1, MS D462, Los Alamos National Laboratory, Los Alamos, New Mexico 87545. \\ **U.S. Geological Survey, Federal Center MS 425, Denver, CO 80225
}

\begin{abstract}
The gradual buildup of rare isotopes from interactions between cosmic rays and atoms in an exposed rock provides a new method of directly determining the exposure age of rock surfaces. The cosmogenic nuclide method can also provide constraints on erosion rates and the length of time surface exposure was interrupted by burial. Numerous successful applications of the technique have been imperative to the complete surface geologic characterization of Yucca Mountain, Nevada, a potential high level nuclear waste repository. The ${ }^{10} \mathrm{Be}$ exposure age of Black Cone lava, within a ten mile radius of the proposed repository site, is $840 \pm 210 \mathrm{kyr}$ (in agreement with previous $\mathrm{K} / \mathrm{Ar}$ dates of $1.0 \pm 0.1 \mathrm{Ma}$ ). Rates of erosion of the tuff bedrock (< $0.4 \mathrm{~cm} / \mathrm{kyr}$ from $7{ }^{10} \mathrm{Be}$ measurements $)$ and of hillslope colluvium $\left(\sim 0.5 \mathrm{~cm} / \mathrm{kyr}\right.$ from ${ }^{10} \mathrm{Be}$ dates on boulder deposits) preclude denudation of the mountain as a concern. Neotectonic concerns (rate of slip and timing of last significant movement along faults) are also being addressed with in situ ${ }^{14} \mathrm{C}$ and ${ }^{10} \mathrm{Be}$ measurements on scarp surfaces and on fault-dissected landforms where no surficial expression of the fault is preserved.
\end{abstract}

\section{INTRODUCTION}

Comprehensive evaluations of the rates and significance of past and continuing geologic processes affecting a candidate site for a terrestrial high level nuclear waste repository are needed to reliably predict how these processes may influence the contained waste in the future. Geologic site characterizations therefore require accurate chronologic control on past and ongoing events or processes. At least 1 million years (Myr) of site geologic history must be stringently examined and the processes identified and quantified if convincing risk analyses for the next 10 thousand years (kyr) are to be obtained.

Unfortunately, reliable chronologies for the last $1 \mathrm{Myr}$ have been difficult to attain due to inherent shortcomings of the dating methods available. Numerous radiometric dating methods exist but very few are suitable for the entire Quaternary time period ( $2.0 \mathrm{Myr}$ ago to the present). Radiocarbon dating is well-accepted by the scientific community but due to the short half-life of ${ }^{14} \mathrm{C},(\sim 5.73 \mathrm{kyr})$, radiocarbon dating can provide numerical ages only for the last $\sim 60$ kyr. Commonly-utilized ${ }^{40} \mathrm{Ar}{ }^{\beta 9} \mathrm{Ar}$ or $\mathrm{K} / \mathrm{Ar}$ dating methods are limited by the very slow decay of radioactive ${ }^{40} \mathrm{~K}$ to ${ }^{40} \mathrm{Ar}$, as low abundances of radiogenic ${ }^{40} \mathrm{Ar}$ in Quaternary rocks are difficult to precisely measure. Most dating methods are limited to specific sampling media, such as organic material for radiocarbon dating, or require knowledge of the thermal and photon history (e.g., thermoluminescence) and other particular qualities (e.g., shells must be identified at the species level for amino acid racemization dating). Many of the available dating methods provide only bracketing ages (i.e., minimum or maximum age limits) that are not sufficiently tight to be useful in evaluating the frequency, rate, or timing of the last occurrence of a particular event.

Over the last decade a new dating method has been developed that provides a means to obtain reliable surface exposure dates for landforms over the entire Quaternary period. The in situ cosmogenic nuclide method provides direct ages of events, not just bracketing ages, so rates and frequencies of processes can be determined more precisely. The technique can also be used to constrain the rates of rock and landform erosion. In this short paper we summarize the cosmogenic nuclide method and describe with examples some of the utility of the technique in geologic site characterization. We report preliminary results from our ongoing work at Yucca Mountain, Nevada, a candidate site for a high-level nuclear waste repository (Fig. 1). 


\section{PRINCIPLES OF THE COSMOGENIC NUCLIDE EXPOSURE HISTORYMETHOD}

The 'in situ cosmogenic nuclide method' is a means of determining rock surface exposure histories from measurements of rare nuclides produced in rocks by cosmic radiation reaching the surface of the Earth. Unlike many other dating methods, the in situ cosmogenic method records the time a rock has been exposed on Earth's surface. In situ cosmogenic nuclides are produced in an exposed rock, not in the atmosphere, as in the case of radiocarbon dating. In situ cosmic-rayproduced nuclides can be either stable (e.g., ${ }^{3} \mathrm{He}$ or ${ }^{21} \mathrm{Ne}$ ) or radioactive (e.g. ${ }^{10} \mathrm{Be},{ }^{14} \mathrm{C}$, ${ }^{26} \mathrm{Al}$, ${ }^{36} \mathrm{Cl}$, or ${ }^{41} \mathrm{Ca}$ ), all with different half-lives. The types and rates of reactions that produce these nuclides vary. In situ ${ }^{10} \mathrm{Be}$ and ${ }^{14} \mathrm{C}$ are produced in quartz from spallation reactions (fission) of the oxygen atoms and to a lesser extent, silicon $[1,2]$. The abundance of a cosmogenic nuclide on a rock surface depends on the chemical composition of the exposed (target) rock, the duration of exposure, the effective production rate of the nuclide in the target material, the rate of decay if the nuclide is radioactive, and the exposure history of the rock being sampled. The most appropriate nuclide (or ratio of nuclides) to measure depends on a variety of factors, most importantly: the rock type, the age of the surface or event, and the particular problem being addressed (i.e., erosion rate or exposure age).

The abundance of a cosmogenic nuclide is the integral of its production rate $(\mathrm{P})$ at the Earth's surface, over the exposure duration $(t)$. Cosmogenic nuclide production rates are not constant. Production rates vary as a function of time because the cosmic ray flux to Earth's surface has fluctuated over time. Production rate increases with geomagnetic latitude due to poleward deflection of cosmic-rays by Earth's geomagnetic dipole field. Production rate also changes with altitude and sample thickness because cosmic rays attenuate (and production rate decreases with depth) through mass they penetrate, in this case the atmosphere and rock [3]. For a young sample, altitude and geomagnetic latitude can be considered approximately invariant and sample thickness can be measured. However, the temporal change in production rate remains an important source of systematic uncertainty in applications of cosmogenic nuclide dating, particularly when comparing surfaces with significantly different ages. For a surface with a simple exposure history, the concentration (atoms. $\mathrm{g}^{-1}$ of mineral or rock) of a stable nuclide can be modeled as:

$$
\mathrm{C}(t)=\mathrm{P} * t+\mathrm{C}_{\mathrm{o}}
$$

where $\mathrm{C}_{\mathrm{o}}$ is the initial or inherited concentration. For samples taken at some depth below the rock surface, or for rock surfaces that have been eroded gradually at a constant rate, the concentration of a spallogenic radionuclide changes with $t$ by:

$$
\mathrm{C}(t)=\frac{P e^{-D_{o} / \Lambda}}{\lambda^{\prime}}\left(1-e^{\lambda^{\prime} t}\right)+\mathrm{C}_{0} e^{\lambda^{\prime} t}, \text { with } \lambda^{\prime}=\lambda\left(1+\frac{\varepsilon \rho}{\lambda \Lambda}\right),
$$

where $\lambda$ is the radionuclide decay constant (e.g. $0.46 \mathrm{Myr}^{-1}$ for ${ }^{10} \mathrm{Be}$ ), $\Lambda$ is the mass attenuation length (approximately $\left.\sim 165 \mathrm{~g} \cdot \mathrm{cm}^{-2}\right), \varepsilon$ is the erosion rate $\left(\mathrm{cm} \cdot \mathrm{yr}^{-1}\right), \rho$ is the density of the rock $\left(\mathrm{g} \cdot \mathrm{cm}^{-3}\right)$, and $D_{\mathrm{o}}$ is the recovery depth of the sample.

Concentrations of the stable nuclides can be measured with a conventional mass spectrometer but measurements of the radionuclides requires accelerator mass spectrometry, AMS. If the concentration of the cosmogenic nuclide can be measured, and its production rate and decay constant are known, and the mass attenuation length for the rock is known, equations (1) and (2) can be rearranged to solve for $t$ or $\varepsilon$. By measuring multiple nuclides in the same sample it is possible to obtain additional information about the erosion rate and exposure history of the rock surface, such as minimum burial durations or time-averaged erosion rates $[4,5]$. The reliability of the calculations is controlled by (i) the validity of the assumptions made (e.g., the effective production rate is known; the initial nuclide concentration was zero, i.e., no inherited concentration; the rock or mineral behaved as a closed system that did not leak or gain a nuclide 
component except though known production or decay pathways; and for age calculations it must be assumed erosion can be compensated for or that there was negligible erosion of the surface); (ii) the effectiveness of the sampling strategy to minimize factors that can influence the in situ production of the nuclide (e.g., complicated surface geometry, burial due to snow or ice cover [6], and shielding of the cosmic rays by nearby structures); and (iii) the precision of the analysis. Single date variances about a mean of dates for a monogenetic landform can be as low as $4 \%$, approaching the present total analytical reproducibility in the nuclide measurement [7].

Presently, the chief uncertainty in cosmogenic nuclide techniques is the difficulty in accurately knowing the cosmic ray flux to a sample site over the exposure duration. Measurements of atmospherically-produced cosmogenic ${ }^{10} \mathrm{Be}$ and ${ }^{14} \mathrm{C}$ preserved in Barbados corals, polar ice cores, and marine and terrestrial sediments show that accumulation rates of these atmospheric isotopes have significant temporal variability. It has been proposed that the changes in cosmic ray fluxes responsible for accumulation rate variations were a result of a fluctuating geomagnetic field strength. Absolute and relative records of geomagnetic paleointensity reveal correlable intensity changes supporting this interpretation. In situ production on Earth, like atmospheric production, can be modeled using the paleointensity records and the relation between cosmic ray flux and paleointensity. Unfortunately, the uncertainties in the dipole paleointensity records are presently too high to confidently adjust the production rates for these nuclides. Several of the most complete records of absolute and relative paleo-intensity over the last 100,000 years are not in general agreement, reflecting the fundamental limitations inherent in the absolute and relative records. Direct measurements in volcanic rocks and fired archeological materials commonly have large uncertainties due to the nonideal magnetic properties (e.g. multidomain magnetizations) of natural materials, discontinuities in the record, and their sensitivity to non-dipole (local) magnetic influences. Continuous (relative) sedimentary records are often even less reliable because of inclination shallowing and other depositional and post-depositional grain reorientation

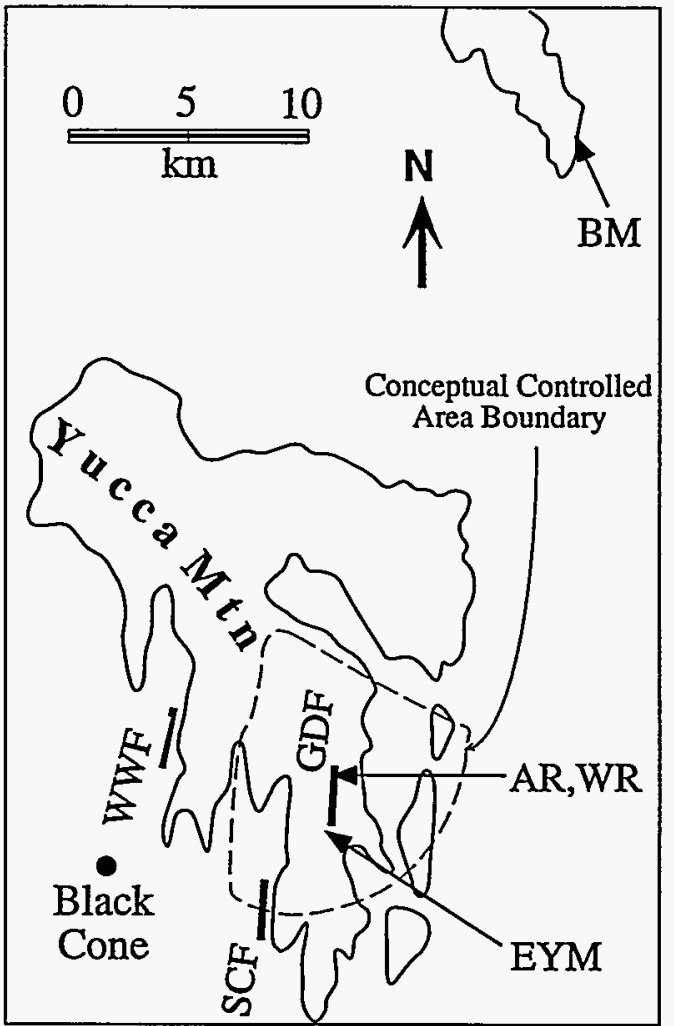

Figure 1. Approximate location of the cosmogenic nuclide sample sites. AR: Antler Ridge; BM: boulder deposit on the southeast flank of Buckboard Mesa; EYM: boulder deposit on the east flank of Yucca Mountain; GDF: trace of a section of the Ghost Dance Fault; SCF: scarp along Solitario Canyon Fault; WWF: scarp along Windy Wash Fault; WR: Whaleback Ridge.

processes. The chronology of both the absolute and relative paleointensity records are an additional source of uncertainty. Nevertheless, it is recognized that time-averaged cosmogenic nuclide production rates on Earth's surface can vary due to paleointensity changes by as much as $20 \%$. However, it is also apparent that for exposure durations greater than $100 \mathrm{kyr}$ (i.e., all samples in this report), the paleointensity shifts (with $\sim 10^{4} \mathrm{yr}$ period) have less affect on the time-averaged production rate because the effects of the shifts are integrated over long time periods. The $\pm 25 \% 1 \sigma$ uncertainty assigned for all ages and erosion rate calculations in this paper is assumed to be a reasonable consideration of all random and systematic errors. "Amore detailed treatment of the uncertainties in these data will be published elsewhere. The reader is referred to [8] for a summary of the state of knowledge and bibliography on production rate variations. 


\section{UTILITY OF COSMOGENIC NUCLIDES IN GEOLOGIC SITE CHARACTERIZATION}

Three fundamental concerns of the geologic surface characterizations of the Yucca Mountain potential nuclear waste repository site (Fig. 1) are (i) long term erosion history of the colluviated hillslopes and the bedrock comprising Yucca Mountain; (ii) the timing of local and regional neotectonic events; and (iii) the age of volcanic landforms within a short radius from the proposed repository site. The following sections describe some of the utility of cosmogenic nuclides in addressing these concerns. The conclusions we report are based on preliminary results and therefore should be considered provisional.

\section{Long-Term Erosion History}

Erosion studies address the concern as to whether the repository might be erosionally breached during the next $100 \mathrm{kyr}$. Cosmogenic nuclides have been used to determine the rate of two styles of erosion on Yucca Mountain: (1) the long-term rate of removal of unconsolidated material on the hillslopes, and (2) the rate of erosion of bedrock on the ridge crests of Yucca Mountain.

To calculate the long-term rate of removal of unconsolidated material on the middle and lower hillslopes of Yucca Mountain, relict boulder deposits on Yucca Mountain and nearby hillslopes were dated (Table I) and the depth of a $50 \mathrm{~m}$ zone on either side of the deposit-and included channel incisions-were measured. Boulder deposits range from wide continuous mantles to isolated narrow bands that are often bounded by gullies. The boulders average from 0.3 to $2 \mathrm{~m}$ diameter and are considered stable if they are firmly positioned and if thick, welldeveloped coatings of desert rock varnish occur on their upper (exposed) surfaces but not on their bases. The boulders may have been deposited from previous gravity-driven block-fall events along cliffs that rise above the boulder deposits (Buckboard Mesa deposit, Table I) or from in situ physical weathering of the underlying bedrock (East Side of Yucca Mountain, Table I). The

Table I. Cosmogenic ${ }^{10}$ Be exposure ages for boulder deposits around Yucca Mountain, Nevada

\begin{tabular}{ccccc}
\hline Sample ID & Location & System & $\begin{array}{c}10 \mathrm{Be} \\
\text { concentration } \\
\text { atom/g }\left(\times 10^{6}\right)\end{array}$ & $\begin{array}{c}\text { T0 Be Age } \\
\text { (kyr) }\end{array}$ \\
\hline JCG022095-003 & BM & 10Be- basalt & 2.67 & $510 \pm 130$ \\
JCG022095-004 & BM & $\begin{array}{c}\text { 10Be- basalt } \\
\text { age }\end{array}$ & 2.95 & $550 \pm 140$ \\
& Deposit & & 540 \\
\hline JCG022295-006 & EYM & 10Be- tuff & 2.29 & $460 \pm 120$ \\
JCG022295-007 & EYM & 10Be- tuff & 1.04 & $210 \pm 50$ \\
JCG022295-008 & EYM & 10Be- tuff & 8.57 & $160 \pm 40$ \\
JCG022295-009 & EYM & 10Be- tuff & 1.09 & $220 \pm 60$ \\
JCG022295-010 & EYM & 10Be- tuff & 6.49 & $120 \pm 30$ \\
& Deposit age & & 460 \\
\hline
\end{tabular}

BM, Buckboard Mesa; EYM, east slope of Yucca Mountain. All sample preparation and ${ }^{10} \mathrm{Be}$ analyses were done on whole rock samples at the University of Pennsylvania [8]. Major elemental abundances on $<75 \mu \mathrm{m}$ fraction was determined using XRF atLos Alamos National Laboratory. Whole rock production rates were calculated relative to production in quartz with estimated $\pm 10 \%$ uncertainty (J. Klein, pers. comm., 1995). ${ }^{10} \mathrm{Be}$ concentrations are normalized for production at sea level and high latitude using [3]. ${ }^{10} \mathrm{Be}$ ages are adjusted for the effects of shielding, which on average decreased production rate by $2.2 \%$ for $\mathrm{BM}$ and $<1 \%$ for EYM due to shielding by local hills. The effect of erosion was considered negligible because the presence of a thick coating of desert rock varnish on the sampled boulders precludes any erosion since varnish formation. Adjustments for geometry (non-horizontal surface) on samples -007 and -009 resulted in a 5\% and $6 \%$ decrease in production rate respectively. The deposit age for $\mathrm{BM}$ deposit is the mean of the two concordant ${ }^{10} \mathrm{Be}$ dates. It represents the maximum age of the deposit because of the ${ }^{10} \mathrm{Be}$ concentration inherited from pre-exposure of the basalts prior to deposition is unknown. The EYM deposit is formed in situ, so the maximum exposure date is taken as the age of the deposit. Complete sample descriptions, analytical results, and production rates used will be published elsewhere. Uncertainty in the ${ }^{10} \mathrm{Be}$ ages reported is $\pm 25 \%$ as discussed in the text. 
boulder deposits may be the oldest (early to middle Quaternary) colluvial hillslope deposits yet dated using cosmogenic nuclides.

The results demonstrate the potential of using cosmogenic nuclides to obtain a chronologic framework in which to interpret Quaternary hillslope evolution throughout the southwestern US. The exposure ages of the boulder deposits date the maximum elapsed time since the last major block-fall events, and were used to calculate a long-term average colluvium erosion rate of $\sim 0.5$ $\mathrm{cm} / \mathrm{kyr}[10],[11]$. If this rate of erosion is projected into the future, gullies approximately $5 \mathrm{~cm}$ deeper than present will be cut into the hillslope over the next $10 \mathrm{kyr}$. It is recognized that the boulders may have been radiated while on the cliff prior to deposition onto the boulder deposit. It can be demonstrated that on the $10 \mathrm{~m}$ vertical cliff above the Buckboard Mesa deposit the production of cosmogenic nuclides by the oblique ray flux onto the surface and some distance behind the cliff face ( 2 to $0.3 \mathrm{~m}$, the diameter of the boulders) would result in an average oblique flux component less than one third that of a vertical flux for this elevation and latitude. The observation that the boulders do not have any weathering rind beneath the varnish coating (possibly suggesting that exposure time on the cliff face was insufficient to form a rind) and the realization that the cliff is definitely retreating since the lava was formed $\sim 2.2 \mathrm{Myr}$ ago, make it likely that the amount of inherited ${ }^{10} \mathrm{Be}$ is no greater than $20 \%$ of the total measured. Additional isotopic work is currently being completed to resolve this further.

On the ridge crests of Yucca Mountain, erosion on exposed bedrock outcrops continues via gradual exfoliation and grusification. A unique and powerful advantage of cosmogenic nuclide techniques over other dating methods is their utility in directly determining the maximum possible rate of bedrock erosion, assuming that erosion proceeded at a gradual and constant rate over the exposure duration. Such an erosion rate can be calculated from the measurement of a single nuclide in multiple surface samples. The concentration of a cosmogenic nuclide is controlled by the erosion of the surface (Equation 2). If the exposure time is considered infinite, the maximum erosion rate that could permit the measured concentration can be calculated. Samples were collected from the crest of two ridge spurs (Antler and Whaleback) on the eastern summit of Yucca Mountain. The maximum possible erosion rates for these bedrock outcrops $(<0.3$ $\mathrm{cm} / \mathrm{kyr}$, Table II) integrates all erosion occurring under all climatic conditions that have existed in the Yucca Mountain area during a significant part of the Quaternary. As the minimum vertical distance above the planned repository is $200 \mathrm{~m}$, the amount of hillslope colluvium and bedrock erosion is significantly less than the level of concern.

\section{Neotectonic Applications}

Two studies have been done for Yucca Mountain site characterization which involved the use of cosmogenic nuclides for investigating neotectonics (tectonic events within the last 5.3 Myr). Three questions are currently being addressed at Yucca Mountain. (1) Did the bedrock scarps exposed along two Quaternary faults form as a result of ruptures within the last $20 \mathrm{kyr}$, and (2) what is the appropriate length of the last surface rupture along those faults (fault segmentation)? (3) Where mapped faults do not have any surface expression (i.e., no scarp), how much time has elapsed since the last scarp-forming event on this fault?

Cosmogenic surface exposure dating of the 1-2 $\mathrm{m}$ high, steep-faced bedrock scarps along the Solitario Canyon and Windy Wash faults was undertaken to verify the field geomorphic evidence which indicates that these bedrock scarps are not young (not $<10 \mathrm{kyr}$ ) tectonic features. The geomorphic evidence suggests that the existing scarps did not result from a recent coseismic displacement of the fault but are more likely older fault scarps that were at one time buried by hillslope colluvium and have been subsequently exhumed and re-exposed [12].

Samples for in situ cosmogenic ${ }^{14} \mathrm{C}$ surface exposure dating were collected from the top and base of the scarp faces at four localities along the Windy Wash fault scarp and three on the Solitario Canyon bedrock scarp (Table III). At sites where the scarp face was greater than $2 \mathrm{~m}$ high an additional sample was collected from the middle of the scarp face. Cosmogenic ${ }^{14} \mathrm{C}$ was measured instead of ${ }^{10} \mathrm{Be}$ because the relatively short half-life of ${ }^{14} \mathrm{C}$ would reduce the effects of any inheritance of the nuclide concentration from the initial (pre-burial) exposure of the scarp 
Table II. Cosmogenic ${ }^{10} \mathrm{Be}$ measurements on bedrock surfaces along ridge crests abutting Yucca Mountain, NV

\begin{tabular}{|c|c|c|c|c|}
\hline Sample ID & Description & $\begin{array}{l}{ }^{10} \mathrm{Be} \text { conc. } \\
10^{6} \text { at } / \mathrm{g}\end{array}$ & $\begin{array}{l}\text { Exposure Age } \\
\text { kyr (tunc) }\end{array}$ & $\begin{array}{l}\text { Max. Erosion Rate } \\
\mathrm{cm} / \mathrm{kyr} \text { (unc) }\end{array}$ \\
\hline CDH-AR-1 & Outcrop above saddle & 4.71 & $1060 \pm 270$ & $0.041(0.028-0.064)$ \\
\hline CDH-AR-5 & In saddle, on footwall near fault & 2.33 & $460 \pm 120$ & $0.11 \quad(0.083-0.16)$ \\
\hline CDH-AR-6 & In saddle, on footwall near fault & 1.95 & $380 \pm 100$ & $0.14 \quad(0.10-0.19)$ \\
\hline CDH-WR-1 & Outcrop above saddle & 3.23 & $680 \pm 170$ & $0.071(0.052-0.10)$ \\
\hline CDH-WR-2 & In saddle, on footwall near fault & 1.08 & $200 \pm 50$ & $0.27 \quad(0.21-0.37)$ \\
\hline CDH-WR-5 & In saddle, on footwall near fault & 1.16 & $210 \pm 50$ & $(0.20-0.35)$ \\
\hline CDH-WR- 6 & In saddle, on hanging wall near fault & 2.80 & $550 \pm 140$ & $0.090(0.067-0.13)$ \\
\hline
\end{tabular}

AR samples, Antler Ridge; WR samples, Whaleback Ridge. All measurements are ${ }^{10} \mathrm{Be}$ AMS analyses on quartz separates from flat and near-horizontal surfaces of tuff outcrops. Concentration has been normalized for production at sea level, $>60^{\circ}$ latitude according to Lal (1991). Complete sample descriptions, analytical data, and production rates used will be published elsewhere. Exposure age assumes no erosion (no shielding or geometry corrections were required). Uncertainties in exposure ages are $\pm 25 \%$ and include random and systematic errors such as uncertainty in effective production rate (see text). Maximum erosion rate is calculated using Eqn. 2 in text, assuming infinite exposure age. The error limits reported for the maximum erosion rates are based on the $25 \% 1 \sigma$ total uncertainties in the analytical measurements and effective production. The erosion calculation assumes a gradual and constant rate over the exposure duration. Saddle refers to negative relief area where Ghost Dance fault plane trends, although there is no surface expression of the fault. ${ }^{10} \mathrm{Be}$ concentration in samples AR1 and WR1 were measured at PRIME Lab. Remaining samples were analyzed at U. of Pennsylvania. Physical and chemical preparation of these samples was conducted by the University of Arizona.

face. All ${ }^{14} \mathrm{C}$ measurements were provided by the University of Arizona NSF-Arizona Accelerator Facility for Isotope Dating.

One sample was also collected from the top of the footwall block, $1 \mathrm{~m}$ back from the scarp face, to evaluate whether or not a significant portion of the ${ }^{14} \mathrm{C}$ concentration measured in the fault scarp samples likely resulted from cosmic rays that may have penetrated the colluvial cover. Although the concentration in this sample was low, suggesting that the concentrations measured on the scarp faces are unlikely to have been produced while the scarp was covered (they were shielded) more measurements on the footwall surface above the scarp are needed before this is . certain. The ${ }^{14} \mathrm{C}$ concentrations measured on the upper part of the scarp face at all 4 sample sites of the Windy Wash fault, and at the base of the scarp face at 2 sites approach saturation (after $20 \mathrm{kyr}$ of exposure, a secular equilibrium is attained when the ${ }^{14} \mathrm{C}$ concentration in the exposed surface is being controlled by the decay of a radionuclide). On the Solitario Canyon scarp the three sample sites are in hillslope drainage channels which dissect the 2-m high scarp faces. At two of the three sites on the upper part of the scarp, the ${ }^{14} \mathrm{C}$ concentration also appears to have reached saturation. The ${ }^{14} \mathrm{C}$ values for samples near the base of the scarp at all three sites, however, represent an exposure history of only a few thousand years. As all sample sites on this scarp lie within the presently active hillslope channels, these low ${ }^{14} \mathrm{C}$ concentrations support the geomorphic evidence which suggests that these features represent recent removal of material away from the base of an ancient scarp by channel erosion. Paleoseismic trench studies on this fault confirm that no Holocene surface ruptures have occured.

Cosmogenic ${ }^{10} \mathrm{Be}$ measurements of samples from the tops of flat and horizontal rock outcrops along the ridge crest of Antler and Whaleback ridges (Table In) have been used to interpret the exposure history of the land surface along ridge crests where the trace of the Ghost Dance fault has been mapped. This north-south-trending fault cuts through the proposed repository site and where it crosses the east-west-trending ridge crests of the study area it possesses no neotectonic surface features, such as bedrock scarps. Instead, the topographic profiles of these ridge crests are smooth and unbroken. A200 m wide saddle occurs on both (and adjacent) ridge crests above the fault trace. The saddle is interpreted to have formed as a result of the difference in bedrock erosion rates of tuff units juxtaposed at the surface by the fault. Samples AR-1 and WR-1 were collected on the crest above the saddle and the remaining samples were collected on the east slope of the saddles. The main trace of the Ghost Dance fault 
Table III. Cosmogenic in situ ${ }^{14} \mathrm{C}$ measurements on bedrock scarps at Yucca Mountain, Nevada

\begin{tabular}{llcc}
\hline Sample ID & \multicolumn{1}{c}{ Location } & $\begin{array}{c}{ }^{14} \mathrm{C} \text { conc. }\left(10^{5}\right. \\
\text { at/g) }\end{array}$ & $\begin{array}{c}\text { Sample Age } \\
\text { (kyr) }\end{array}$ \\
\hline WWF1-1 & Top of scarp & saturated & $>20$ \\
WWF1-2 & Base of scarp & saturated & $>20$ \\
WWF2-1 & Top of scarp & saturated & $>20$ \\
WWF2-2 & Middle of scarp & 1.96 & 10.3 \\
WWF2-3 & Base of scarp & saturated & $>20$ \\
WWF3-1 & Top of boulder & .83 & 3.3 \\
WWF3-2 & Front of boulder & 1.5 & 2.9 \\
WWF4-2 & Top of scarp & saturated & $>20$ \\
WWF4-3 & Base of scarp & 0.0 & 0.0 \\
\hline & & & \\
SCF 1-2 & Middle of scarp & saturated & $>20$ \\
SCF 1-3 & Base of channel & 1.5 & 4.0 \\
SCF 2-1 & Top of scarp & saturated & $>20$ \\
SCF 2-2 & Base of scarp & saturated & $>20$ \\
SCF 2-3 & Back of scarp & 1.12 & 2.1 \\
SCF 4-3 & Top of scarp & 1.49 & 5.7 \\
SCF 4-1 & Base of scarp & 0.85 & 3.1 \\
\hline
\end{tabular}

WWF, Windy Wash Fault; SCF, Solitario Canyon Fault. In situ cosmogenic ${ }^{14} \mathrm{C}$ measurements were made on whole rock samples at the NSF AMS facility at University of Arizona. The details and geologic relevance of these data are discussed thoroughly in [11]. 'Saturation' indicates that the sample is interpreted to have contained the maximum possible concentration of in $\operatorname{situ}{ }^{14} \mathrm{C}$ assuming no erosion or burial, i.e., the system reached secular equilibrium so the abundance of ${ }^{14} \mathrm{C}$ was being controlled by the decay of ${ }^{14} \mathrm{C}$.

across Antler and Whaleback ridge lies between the sites where samples AR-5 and AR-6 and WR5 and WR- 6 were collected. The ${ }^{10} \mathrm{Be}$ exposure ages along the two ridge profiles indicate that erosional equilibrium of the crest surfaces has existed for at least $200 \mathrm{kyr}$. The time since the last scarp-forming event must also be more than $200 \mathrm{kyr}$, the minimum time necessary to remove the bedrock scarp and for the surface to attain equilibrium. Three additional provisional ${ }^{10} \mathrm{Be}$ measurements along the Antler Ridge profile (analyses in progress at PRIMELab, personal communication with T. Jull, 1995) support these conclusions.

\section{Volcanic Histories}

Cosmogenic ${ }^{10} \mathrm{Be}$ surface exposure dates on Quaternary lavas and other volcanic landforms enhance the identification of spatial and temporal trends in volcanic activity in the Yucca Mountain region. Six middle to late Quaternary $(<1 \mathrm{Myr})$ cinder cones and associated flows are present within $20 \mathrm{~km}$ of Yucca Mountain. A number of dating methods, including cosmogenic ${ }^{3} \mathrm{He}$ and ${ }^{36} \mathrm{Cl}$ work by others [13], have been used to constrain the timing of volcanic events at Lathrop Wells, the youngest center in the Yucca Mountain area. One sample collected from a pressure ridge on a basalt flow at Black Cone, west side of Yucca Mountain has been dated. The wholerock ${ }^{10} \mathrm{Be}$ exposure age, assuming no recent erosion of the rock surface because of the presence of thick continuous coatings of rock varnish, is $840 \pm 210 \mathrm{kyr}$. The measured ${ }^{10} \mathrm{Be}$ could have originated only from cosmic-ray exposure of the lava surface after the flow cooled (i.e. the initial concentration prior to exposure is zero). The mean of three ages of mineral closure determined by the K/Ar method are 1.0 $\pm 0.1 \mathrm{Myr}$ [13]. Although these two ages are statistically concordant, the exposure age may be younger than the K/Ar age by $470 \mathrm{kyr}$. This difference can be attributed to erosion of the lava surface. The maximum average erosion rate of the lava assuming the lower $1 \sigma^{10} \mathrm{Be}$ age of $630 \mathrm{kyr}$ and the higher $\mathrm{K} / \mathrm{Ar}$ age of $1.1 \mathrm{Myr}$ is $0.05 \mathrm{~cm} / \mathrm{kyr}$. 
Cosmogenic nuclide techniques can be used to determine the exposure age of essentially any landform. Various different mineral phases can be used or whole rock analyses can be done, so lithology is not a limiting factor. Stable nuclides and radionuclides with a large range of decay rates make it the only method able to reliably date surfaces with exposure ages from $10^{3}$ to $>10^{7}$ years (i.e., the entire Quaternary) depending on the complexity of the surface exposure history. Single and multiple nuclide measurements can be used to gain insight on rock erosion rates, landform erosion, style of erosion, and other surface history characteristics. In the Yucca Mountain region, several cosmogenic nuclides have been measured to gain insight into the age of basaltic volcanism, the timing and frequency of faulting, the stability of slope surfaces, and the rate at which Yucca Mountain is eroding by vertical erosion and cliff and hillslope retreat. The ability of multinuclide methods to help constrain erosion rates is also particularly useful for site characterizations in glaciated regions where erosion is manifest by subglacial plucking of blocks.

There are several geologic factors that influence the datability of a surface. If the surface has suffered erosion, has been buried during its exposure, is subhorizontal, has a complicated geometry, has been re-oriented, or has been otherwise partially shielded from cosmic rays during its bombardment duration, the exposure age calculated with most cosmogenic nuclides will generally be younger than the actual age. If the initial concentration of a nuclide is not zero when the exposure event of interest began, the calculated exposure age will be older than the actual age of the event. It is typically difficult to prove that there are no unaccounted inherited nuclide components, but geologic reasoning can often be used to support this assumption (i.e., lavas do not have inherited concentrations). These geologic factors and uncertainties in the nuclide production rates must be considered when using cosmogenic nuclides for site characterizations.

\section{ACKNOWLEDGEMENTS}

The studies providing the reported data were sponsored by the Department of Energy's Yucca Mountain Project In Las Vegas, Nevada. Field work has continued since 1984. We thank A. Murphy, J. Klein, T. Jull, N.Lifton, B. Phillips, P. Sharma, and S. Vogt for analyses or discussions.

\section{REFERENCES AND NOTES}

1. K. Nishiizumi, et al., J. Geophys. Res. 94, 17907-17915 (1989).

2. A. J. T. Jull, N. Lifton, W. M.Phillips, J. Quade, Nucl. Instr. Meth. Phy.s Res. B, 308-310 (1994).

3. D. Lal, Earth and Planetary Science Letters 104, 424-439 (1991).

4. K. Nishiizumi, et al., Earth and Planetary Science Letters 104, 440-454 (1991).

5. For similar treatment of other erosion rate data see [4]; Macciaroli, P., PhD. Dissertation, Univ. Pennsylvania, Philadelphia, 1995; J. C. Gosse, D. R. Grant, J. Klein, B. Lawn, CANQUA-CGRG Conf. Abstr., Memorial Univ. of Newfoundland, St. Johns, CA19 (1995).

6. J. C. Gosse, E. B. Evenson, J. Klein, B. Lawn, R. Middleton, Geology 23, 877-880 (1995).

7. J. C. Gosse, J. Klein, E. B. Evenson, B. Lawn, R. Middleton, Science 268, 1329-1333 (1995).

8. J. C. Gosse, C. Harrington, R. Reedy, Radiocarbon, May, 1996, proceedings review, (accepted).

9. Total (whole rock) chemistry was used because the low abundance $(<3 \%)$ and fine-grained nature of the quartz in the tuff made it unfeasible to separate a sufficient mass of the mineral from the tuff. This demonstrates the universal nature of the cosmogenic dating tool. The ${ }^{10} \mathrm{Be}$ whole rock production rates were calculated using production rates estimated for production from the major elements in the tuff [J. Klein, pers. commun., 1995]. The whole rock production rates ranged from $90 \%$ to $95 \%$ of the rate for pure quartz and the estimated $1 \sigma$ uncertainty is $\sim 10 \%$.

10. J. W. Whitney, C. D. Harrington, GSA Bulletin 105, 1008-1018 (1993).

11. US Department of Energy, Topical Report: Evaluation of the potentially adverse condition "Evidence for extreme erosion during the Quaternary Period at Yucca Mountain, Nevada" (1993), Vol. YMP/92-41-TPR.

12. C. D. Harrington, J. W.Whitney, A. J. T. Jull, W.Phillips, USGS Circular (accepted).

13. B. Crowe, et al., Status of volcanism studies for the Yucca Mountain Site Characterization Project, Los Alamos National Laboratory Report (Los Alamos, NM, 1995), Vol. LA-12908-MS. 


\section{DISCLAIMER}

This report was prepared as an account of work sponsored by an agency of the United States Government. Neither the United States Government nor any agency thereof, nor any of their employees, makes any warranty, express or implied, or assumes any legal liability or responsibility for the accuracy, completeness, or usefulness of any information, apparatus, product, or process disclosed, or represents that its use would not infringe privately owned rights. Reference herein to any specific commercial product, process, or service by trade name, trademark, manufacturer, or otherwise does not necessarily constitute or imply its endorsement, recommendation, or favoring by the United States Government or any agency thereof. The views and opinions of authors expressed herein do not necessarily state or reflect those of the United States Government or any agency thereof. 